\title{
Clay and fibers: Energy efficiency in buildings between tradition and innovation
}

\author{
T. Cardinale*, C. Sposato, A. Feo, P. De Fazio \\ ENEA - C.R. Trisaia, Div. DTE-BBC - ss 106 jonica km. 419, 500 Rotondella, Italy
}

Corresponding Author Email: tiziana.cardinale@enea.it

https://doi.org/10.18280/mmep.050308

Received: 2 May 2018

Accepted: 14 June 2018

\section{Keywords:}

adobe bricks, biobased materials, mechanical strength, natural fibers, thermal conductivity

\begin{abstract}
Building construction technology using clay soil in various forms, already known since ancient times, presents a great potential to regulate indoor humidity, to reduce the indirect impact of construction sector on the environment and on energy consumption. Extensive studies have also been done on the effects of natural fibers on the mechanical and physical behaviour of composite materials in terms of strength, energy efficiency and impact resistance. This work is focused on some natural fiber composites made from different mixtures containing clay soil with different percentages of jute, straw and basalt fibers, in order to determine the ideal mixture between clay and fibers providing the optimum values of thermal inertia, mechanical performance and shrinkage able to improve the energy efficiency of buildings. The mechanical, physical and thermal properties of some specimens have been investigated. The obtained results show an improved mechanical strength and a better thermal conductivity of the clay composite material.
\end{abstract}

\section{INTRODUCTION}

Building with low-input materials from renewable resources is one of the key issues for the EU; for this reason several ambitious actions have been implemented to reduce the impact of construction sector on energy consumption and, more generally, on the environment.

The promotion of sustainable development lead to a growing interest in "alternative" building materials such as crude earth and biomass aggregates.

Clay soil is one of the most common materials and the socalled adobe bricks made from loam, clay and sand were widely used in the past mostly for housing construction. Still from the Neolithic period, there are evidences of the existence of such constructions in areas like Mesopotamia, Anatolia and the Levant [1].

Nowadays crude earth is still the most widespread building material in the world because it has advantages in energy and climate fields: it is available in large quantities, cheap and easy to work, it is a totally recyclable resource and it requires a very low amount of energy to the manufacture as well to the transport [2].

Other important benefits, as observed in raw earth constructions left by previous generations, are the high thermal inertia and humidity regulation properties, that improve thermal performances and provide a healthy environment within the buildings [3].

Studying the hygro-thermal properties of this kind of biobased materials is an essential step in the evaluation process of their impact, not only on energy consumption for heating, but also on indoor comfort, which strongly depends on heat and steam transfer [4].

In recent years the use of these type of local resources combined with natural fibers has contributed to create new low cost environmentally friendly materials, characterized by better electrical resistance, good mechanical properties, good thermal and acoustic insulating properties, as well as higher resistance to fracture [5].

The design of natural fiber composites could really substitute synthetic fiber reinforced composites as structural or semi structural components, especially in lightweight applications, with many economic and environmental benefits.

The interest of researchers [6] toward natural fiber composites is principally due to avoid harmful effect on the environment and is also connected to their specific properties.

They are biodegradable, inexpensive, affordable, green, accessible and easy available in nature, such as coconut tree, banana tree, cotton, flax, hemp, straw, jute, etc. [7]

Among natural fibers, the lignocellulosic ones containing cellulose, hemicellulose, lignin and pectins, with a small amount of extractives (the relative amounts vary greatly between different species of plants, depending on their origin) are well characterized in terms of composition and mechanical properties [8].

Also basalt fibers, natural inorganic material, represent a very promising reinforcing agent for these building materials [9-10].

In the last decades, extensive studies have been done especially on the effects of natural fibers on the mechanical and physical behaviour of cementitious materials in terms of strength, energy efficiency, and impact resistance [11-12]. The inclusion of short discrete fibres in concrete, mortar and/or cement paste can largely enhance some of their engineering properties, such as fracture toughness, tensile strength, flexural strength, resistance to fatigue, impact, and thermal shock [13].

Use of natural fibers to produce high-quality and low cost sustainable fiber-reinforced material is increasing. The mechanical properties of composite materials are strongly influenced by the kind of fiber and its properties [14].

Compared with conventional inorganic fillers such as glass fibers and carbon fibers, natural fibers provide additional 
advantages: low cost production, less energy consumption, flexibility during processing and less resulting machine wear, low density and relatively high tensile and flexural modulus are the main reasons behind the use of cellulose fibers as a constituent of the natural fiber composites [15-16].

The renewable and biodegradable characteristics of natural fibers facilitate their ultimate disposal by composting or incineration, options not possible with most industrial fibers [17].

Interventions on the building envelope represent an energy and cost effective solution, and also play an important role in achieving better conditions for the users, as far as thermal, visual and acoustic comfort as well as indoor air quality are concerned [18-19].

Therefore low carbon construction process would be an economic and ecological challenge with multiple benefits.

In this work we have produced a clay sand composite with natural filler, such as basalt, jute or straw, in different percentages, in order to provide building materials with good physical, mechanical and thermal properties.

\section{MATERIALS AND METHODS}

The book size will be in A4 (8.27 inches x 11.69 inches). Do not change the current page settings when you use the template.

The number of pages for the manuscript must be no more than ten, including all the sections. Please make sure that the whole text ends on an even page. Please do not insert page numbers. Please do not use the Headers or the Footers because they are reserved for the technical editing by editors.

The materials used for the specimens made as adobe bricks are clay, sand water and fillers such as basalt, jute and straw.

Clay is a finely-grained soil material, used as binder. It has as major components (wt\%): $\mathrm{SiO} 2$ (57.29\%), $\mathrm{Al} 2 \mathrm{O} 3$ (12.79\%), $\mathrm{CaO}(18.48 \%)$.

The chemical composition of used clay is reported in table 1 and particle size distribution is shown in figure 1 .

Table 1. Chemical composition of clay

\begin{tabular}{cc}
\hline Substance & \% w/w \\
\hline $\mathrm{SiO}_{2}$ & 57.29 \\
$\mathrm{Al}_{2} \mathrm{O}_{3}$ & 12.79 \\
$\mathrm{TiO}_{2}$ & 0.58 \\
$\mathrm{Fe}_{2} \mathrm{O}_{3}$ & 5.48 \\
$\mathrm{CaO}$ & 18.48 \\
$\mathrm{MgO}$ & 1.43 \\
$\mathrm{~K} 2$ & 2.13 \\
$\mathrm{Na}_{2} \mathrm{O}$ & 0.57 \\
$\mathrm{SO}_{3}$ & 1.26 \\
\hline
\end{tabular}

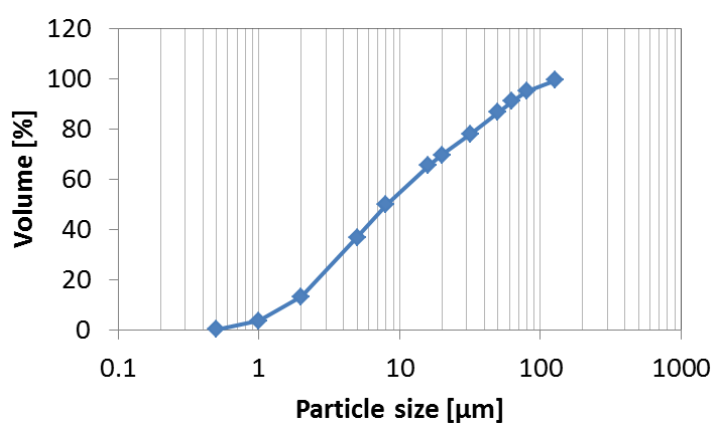

Figure 1. Size distribution of clay particles
The XPRD (X-ray powder diffraction) analysis (Figure 2) shows the presence of crystalline phases such as quartz, dolomite, calcite, plagioclase, illite, chlorite and kaolinite.

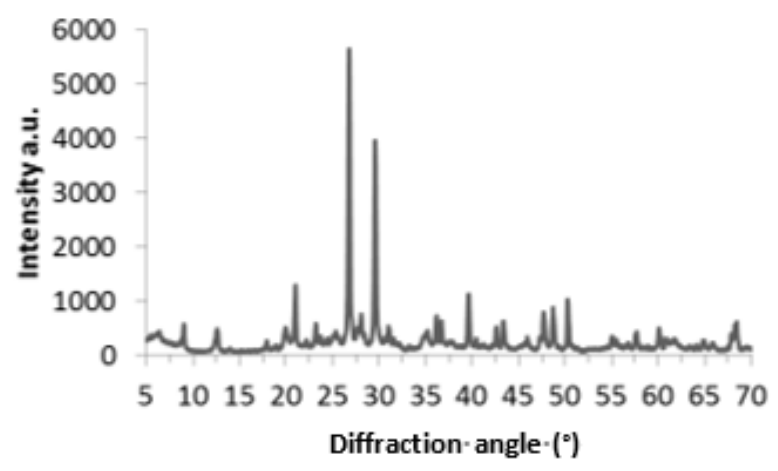

Figure 2. XRD patterns of clay

In this work, tap water is added to fine silica sand in order to perform specimens with different clay content (up to $50 \% \mathrm{w} / \mathrm{w})$; the particle size distribution of sand is measured according with UNI EN 933-1:2012 and showed in Figure 3.

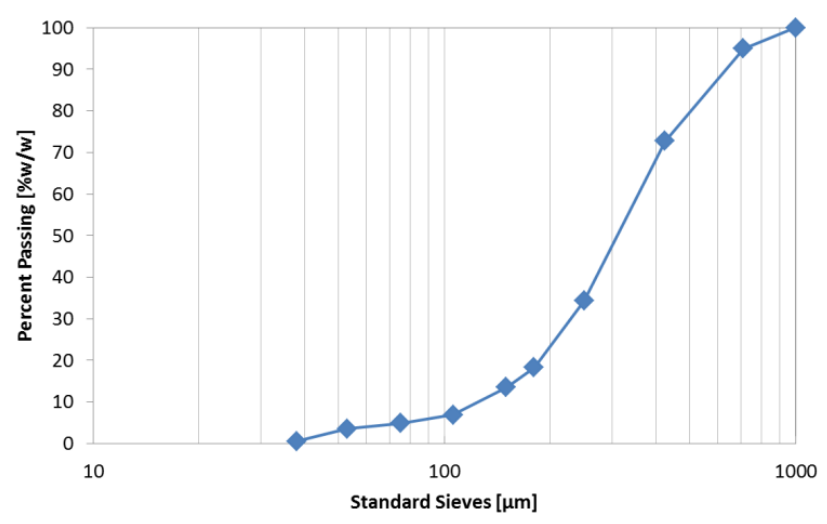

Figure 3. Size distribution of sand particles

The straw fillers used for this research have been obtained from plants of durum wheat (Triticum durum Desf.), characterized by medium height and late production.

Straw is a very good and renewable thermal insulation material [20], cheap and easy to obtain.

The straw used in this research has been produced at the end of June 2015, in the form of compacted bales of approximate dimensions, stored in a dry environment, cut by using a knife mill with a $2 \mathrm{~mm}$ square grid and finally characterized by ASTM sieves (Figure 4, Figure 5).

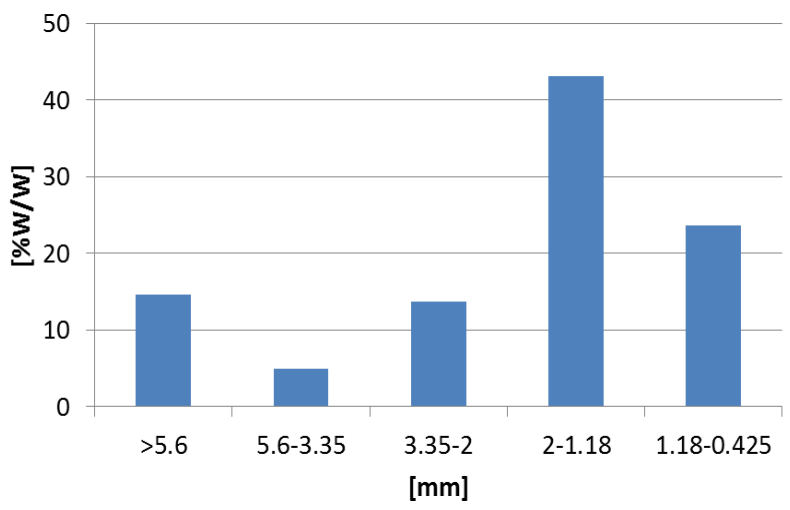

Figure 4. Size distribution of straw fibers particles 


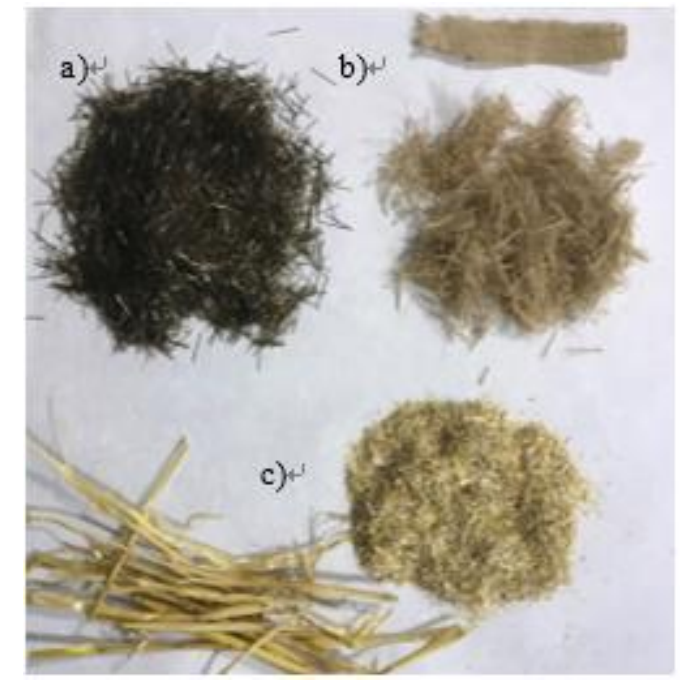

Figure 5. Fillers used for the mixture; a) basalt, b) jute, c) straw

The jute fibers were obtained by manually cutting a canvas of $1 \times 1 \mathrm{~m}$. The length of resulting fibers was $3( \pm 0.5) \mathrm{cm}$ with a thickness of about $1 \mathrm{~mm}$.

Basalt fibers were provided by the Chinese company HG GBF. Chopped used in this work were $24 \mathrm{~mm}$ of length and $12 \mu \mathrm{m}$ of thickness (fiber code J01YF6) (Figure 5).

The bulk densities of the straw, jute and basalt fibers were determined by weighing a known volume of material; true density was determined after soaking the fibers overnight in pure water. In Table 2 the fillers densities are reported.

Table 2. Densities of used fibers

\begin{tabular}{cccc}
\hline & $\begin{array}{c}\text { Bulk density } \\
{\left[\mathbf{k g} / \mathbf{m}^{\mathbf{3}}\right]}\end{array}$ & $\begin{array}{c}\text { Apparent } \\
\text { density } \\
{\left[\mathbf{k g} / \mathbf{m}^{\mathbf{3}}\right]}\end{array}$ & $\begin{array}{c}\text { True } \\
\mathbf{d e n s i t y} \\
{\left[\mathbf{k g} / \mathbf{m}^{\mathbf{3}}\right]}\end{array}$ \\
\hline Jute & 30 & 570 & 1200 \\
Basalt & 120 & 1800 & 2300 \\
Straw & 105 & 530 & 590 \\
\hline
\end{tabular}

\subsection{Specimens preparation}

In this work two different specimens geometries were prepared; the first one are $160 \times 40 \times 40 \mathrm{~mm}$ clay bricks, used for mechanical test, and the second one are $300 \times 300 \times 20 \mathrm{~mm}$ specimens used to investigate the thermal properties of resulting materials.

In a first part of this work the influence of clay mass was studied; for this purpose $160 \times 40 \times 40 \mathrm{~mm}$ specimens with mixture components amounts reported in Table 3 were prepared.

Table 3. Composition of clay/sand mixture

\begin{tabular}{ccccc}
\hline & Sand $[\mathbf{g}]$ & Clay $[\mathbf{g}]$ & Water $[\mathbf{g}]$ & $\begin{array}{c}\text { Density } \\
{\left[\mathbf{k g} / \mathbf{m}^{\mathbf{3}}\right]}\end{array}$ \\
\hline C10 & 1350 & 150 & 375 & 1560 \\
C20 & 1200 & 300 & 375 & 1680 \\
C30 & 1050 & 450 & 375 & 1650 \\
C40 & 900 & 600 & 375 & 1700 \\
C50 & 750 & 750 & 375 & 1790 \\
\hline
\end{tabular}

The amount of clay, calculated as a percentage on dry raw material, varied between 10 and $50 \%$ (C10 - C50). A water/solid ratio of 0.25 is used in order to obtain an appropriate workability of mixture.

In a typical preparation step, dry solid, such as sand and clay, are mixed with tap water using a concrete mixer impeller (800 $\mathrm{rpm}$ ) for $10 \mathrm{~min}$. The mixture was placed into appropriate moulds, and the resulting samples are aged in a climate chamber (Angelantoni mod. ACS 1200) for 3 days at $30{ }^{\circ} \mathrm{C}$ with a relative humidity (U) of $40 \%$ and then increasing temperature up to $70{ }^{\circ} \mathrm{C}$. After aging treatment no weight variation was observed.

Specimens containing fibers were prepared using the components reported in Table 4.

Table 4. Composition of fiber specimens

\begin{tabular}{ccccccc}
\hline & S2 & S3 & J2 & J3 & B2 & B3 \\
\hline Sand [g] & 936 & 924 & 936 & 924 & 936 & 924 \\
Clay [g] & 240 & 240 & 240 & 240 & 240 & 240 \\
Water [g] & 310 & 400 & 375 & 400 & 310 & 320 \\
$\quad$ Straw & 24 & 36 & - & - & - & - \\
fillers [g] & & & & & & \\
$\begin{array}{c}\text { Jute fibers } \\
\text { [g] }\end{array}$ & - & - & 24 & 36 & - & - \\
$\quad$ Basalt & & & & & & \\
fibers [g] & - & - & - & - & 24 & 36 \\
\hline
\end{tabular}

Prepared samples contain an amount of fiber of 2 and $3 \% \mathrm{w} / \mathrm{w}$ calculated on dry solid raw materials. The content of clay was $20 \% \mathrm{w} / \mathrm{w}$ for all specimens reported in Table 4 . In order to guarantee the workability of clay/fiber mixture an increase of water/solid ratio is effected, from $25.8 \%$ in the case of the lowest basalt content (B2), to $33.3 \%$ for the highest amount of straw (S3) and jute fillers (J3).

In Table 5 the composition of mixtures used for $300 \times 300 \times 20 \mathrm{~mm}$ panel specimens is shown; $3-5 \%$ of fiber content were studied, using 0.2 of clay/solid ratio.

Table 5. $300 \times 300 \times 20 \mathrm{~mm}$ panel samples characteristics

\begin{tabular}{cccccc}
\hline & $\begin{array}{c}\text { Sand } \\
{[\mathbf{g}]}\end{array}$ & $\begin{array}{c}\text { Clay } \\
{[\mathbf{g}]}\end{array}$ & $\begin{array}{c}\text { Water } \\
{[\mathbf{g}]}\end{array}$ & $\begin{array}{c}\text { Fiber } \\
{[\mathbf{g}]}\end{array}$ & $\begin{array}{c}\text { Density } \\
{\left[\mathbf{k g} / \mathbf{m}^{3}\right]}\end{array}$ \\
\hline REF-p & 2400 & 600 & 750 & - & 1700 \\
S3-p & 2310 & 600 & 775 & 90 & 1450 \\
S5-p & 2250 & 600 & 775 & 150 & 1280 \\
J3-p & 2310 & 600 & 1000 & 90 & 1460 \\
J5-p & 2250 & 600 & 1000 & 150 & 1310 \\
B3-p & 2310 & 600 & 800 & 90 & 1690 \\
B5-p & 2250 & 600 & 800 & 150 & 1490 \\
\hline
\end{tabular}

\section{SECTION HEADINGS}

Experimental tests were performed to investigate thermal and mechanical properties of manufactured specimens containing different percentages of used fibers. The apparatus used for thermal conductivity measurements was an heat flow meter in "single sample in a double configuration" (NETZSCH heat flow meter HFM 436/0/1), placed in a conditioned laboratory at a temperature of $23 \pm 2{ }^{\circ} \mathrm{C}$ and relative humidity $50 \pm 5 \%$, to ensure the test conditions required by the standard EN 12664:2002 "Thermal performance of building and products - Determination of thermal resistance by means of guarded hot plate and heat flow meter methods - Dry and moist products of medium and low thermal resistance".

The specimen is placed between two plates at different 
temperatures $(\Delta \mathrm{T})$

The heat flux (q) which passes through the specimen is measured by heat flux transducers: with the achievement of thermal equilibrium the test ends. For the purpose of the analysis only a central portion $(100 \times 100 \mathrm{~mm})$ is considered.

If $\lambda$ is the thermal conductivity of the specimen, $d$ is the specimen thickness, $\Delta \mathrm{T}$ is the temperature difference between the two faces of the test and A is the area through which the heat passes, the relation between these parameters which provides heat balance is expressed by Fourier equation:

$\Phi=\lambda \cdot \mathrm{A} \cdot \Delta \mathrm{T} / \mathrm{d}$

The two transducers measure the heat flow through the specimen. The signal from a transducer (expressed in Volt) is proportional to the heat flow through the transducer.

In the heat flow meter, the transducer area is the area through which passes the heat and is constant for all the specimens, then:

$\Phi=\mathrm{N} \cdot \mathrm{V}$

where $\mathrm{N}$ is the calibration factor that joins the potential difference of the transducers to heat flow through the specimen. Resolving isolating $\lambda$, thermal conductivity is given by the following relation:

$\lambda=\mathrm{N} \cdot \mathrm{V} \cdot \mathrm{d} /(\Delta \mathrm{T} \cdot \mathrm{A})$

Average temperature of equilibrium of tests is set to $10^{\circ} \mathrm{C}$ and the $\Delta \mathrm{T}$ between the plates is $20^{\circ} \mathrm{C}$.

In order to investigate the mechanical properties of clay specimens containing fillers, three samples $(160 \times 40 \times 40 \mathrm{~mm}$ dimensions) for each mixture were prepared for flexural and compressive strength tests, according to standard EN 1015-11 "Methods of test for mortar for masonry - Determination of flexural and compressive strength of hardened mortar".

The test apparatus used was a frame Dual Column Instron 3369 for both flexural and compressive strength.

Regarding flexural tests, the instrumentation applies the load at a rate specified in standard UNI 1015-11; in this step load rate was set to $50 \mathrm{~N} / \mathrm{s}$ since for these plaster mortars a low resistance is expected.

For each specimen the maximum applied load (F) was recorded and expressed in Newton, then flexural strength (f) was calculated in $\mathrm{N} / \mathrm{mm} 2$, to the nearest $0.05 \mathrm{~N} / \mathrm{mm} 2$ using the following equation:

$f=1.5 \cdot F \cdot 1 /(b \cdot d 2)$

where:

$\mathrm{b}=$ width of the specimen $(\mathrm{mm})$

$\mathrm{d}=$ depth of the specimen $(\mathrm{mm})$

$1=$ distance between the axes of the support $(\mathrm{mm})$.

The average flexural strength was calculated to the nearest $0.1 \mathrm{~N} / \mathrm{mm}^{2}$.

In compression tests the load rate was set around to $300 \mathrm{~N} / \mathrm{s}$, according to standard EN 1015-11.

For each specimen the maximum load applied (N) was recorded and expressed in Newton; the compressive strength $(\sigma)$ was calculated to the nearest $0.05 \mathrm{~N} / \mathrm{mm} 2$ as the maximum load carried by the specimen divided by its cross-sectional area.

For all realized mixtures, average of compressive strength has been calculated to the nearest $0.1 \mathrm{~N} / \mathrm{mm} 2$.

\section{RESULTS AND DISCUSSION}

Experimental tests were performed to obtain thermal and mechanical properties of some specimens containing different percentages of clay and fibers.

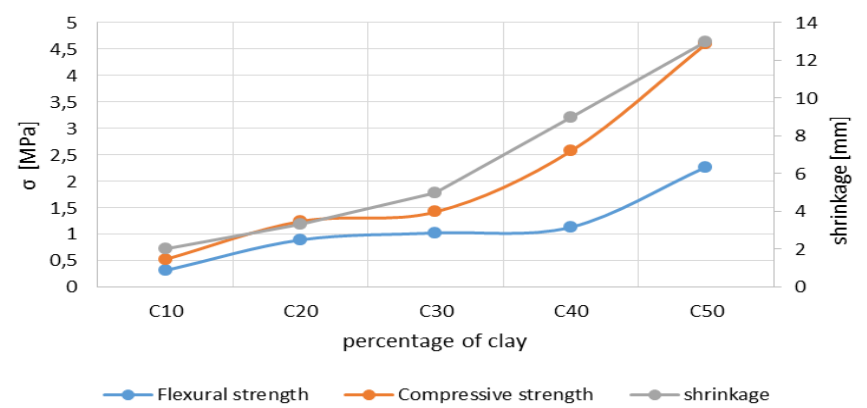

Figure 6. Results of mechanical tests on clay specimens

The Figure 6 shows the flexural and compressive breaking strength of clay specimens, C10 - C50, also related to the shrinkage expressed in millimeter.

The compression and flexural strength increases with the increasing of clay content; the same behavior is observed for the shrinkage. This is the typical behavior of clay and sand artifacts [1].

The shrinkage is an important parameter for the production process of clay specimens

In order to study the effect of fillers in sand/clay mixtures, we decided to use a $20 \%$ of clay specimens with fibers, looking for a compromise between mechanical strength and shrinkage.

The flexural stress-strain curves shown in Figure 7 indicate the fragile behavior of adobe bricks.

In fragile materials the break occurs without any noticeable change in the elongation rate.

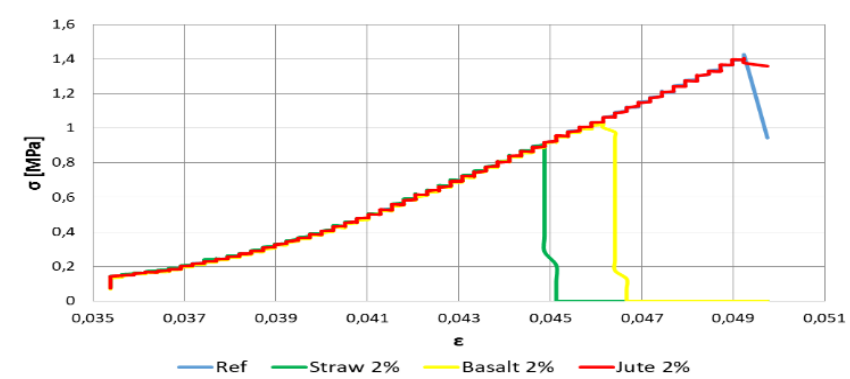

Figure 7. Flexural stress-strain curves

The second column of table 6 shows the average flexural breaking strenght (expressed in MPa) of the REF specimen (without fibers) and of the specimens with the fibres. The third one shows the percentage variation of the strength with respect to the REF one.

The use of straw in the clay and sand mixture causes a decrease in the maximum flexural strength, if compared to the REF specimen.

Moreover, the flexural strength decreases with the fiber amount increasing; in particular we observe a resistance reduction of $24 \%$ for higher content straw specimen (S5).

On the contrary the flexural strength rises with fiber content, respect to the REF one, in the case of basalt and jute specimens.

In particular, using the basalt fibers (B2-B3), the increase in mechanical strength increases with the amount of filler, while the enhancement of jute from 2 to $3 \%(\mathrm{~J} 2-\mathrm{J} 3)$ implies that the 
value of the flexural strength is almost unchanged.

Basalt fibers and jute fillers increase the mechanical performance of reinforced adobe bricks exhibiting a binder behavior; the presence of straw fillers only influence the density of the final product [14].

Table 6. Average flexural breaking strength

\begin{tabular}{ccc}
\hline Sample & $\begin{array}{c}\text { Flexural strength } \boldsymbol{\sigma} \\
{[\mathbf{M P a}]}\end{array}$ & \begin{tabular}{c}
$\boldsymbol{\sigma}-\boldsymbol{\sigma}_{\text {ref }}$ \\
\cline { 3 - 3 } $\boldsymbol{\sigma}_{\text {ref }}$
\end{tabular} \\
\hline REF & 0.85 & - \\
S2 & 0.84 & $-1 \%$ \\
S3 & 0.78 & $-8 \%$ \\
S5 & 0.65 & $-24 \%$ \\
B2 & 0.87 & $2 \%$ \\
B3 & 1.15 & $35 \%$ \\
J2 & 1.19 & $40 \%$ \\
J3 & 1.28 & $41 \%$ \\
\hline
\end{tabular}

The second column of table 7 shows the average compression breaking strength of the REF specimen and of the specimens with the used fillers. The third column shows the percentage variation of the strength with respect to the REF one.

Table 7. Compression breaking strength

\begin{tabular}{|c|c|c|}
\hline Sample & $\begin{array}{c}\text { Compressive strength } \sigma \\
{[\mathrm{MPa}]}\end{array}$ & $\frac{\sigma-\sigma_{\text {ref }}}{\sigma_{\text {ref }}}$ \\
\hline REF & 1.32 & - \\
\hline S2 & 1.24 & $-6 \%$ \\
\hline S3 & 1.18 & $-11 \%$ \\
\hline S5 & 0.79 & $-40 \%$ \\
\hline B2 & 1.41 & $7 \%$ \\
\hline B3 & 1.67 & $27 \%$ \\
\hline $\mathrm{J} 2$ & 1.57 & $19 \%$ \\
\hline
\end{tabular}

The behavior of the samples under compressive strength is similar to the flexural one. The increase of straw causes a decrease in the maximum compression strength, while the presence of basalt and jute improves the mechanical performance of the material.

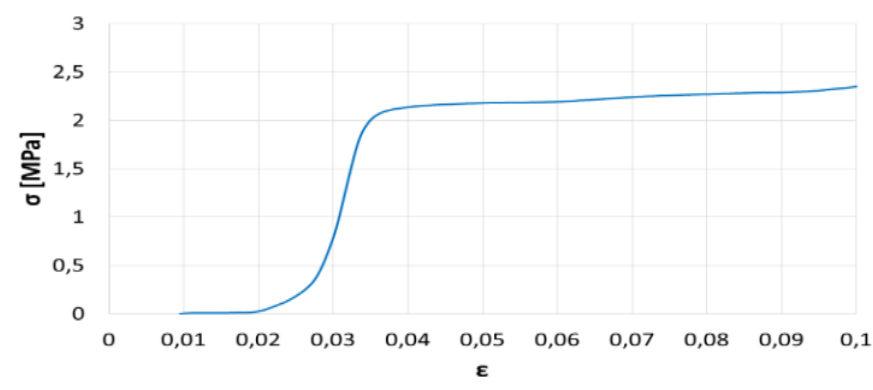

Figure 8. Stress strain diagram of J2 specimen

Figure 8 shows the stress strain diagram of a specimen with $2 \%$ of jute. The trend of the curve, representative of all the samples containing jute as filler, shows a first linear section, up to the inflection where there is the collapse of the sand/clay matrix, and a second linear one where the material presents a plastic behavior with a low increasing compression strength.

The presence of jute avoids the disintegration of the clay matrix, probably acting as a link/bridge between the clay crystals.
Table 8. Values of $\lambda$

\begin{tabular}{ccc}
\hline Sample & Thermal conductivity $\lambda\left[\mathbf{W} /\left(\mathbf{m}^{2} \mathbf{K}\right)\right]$ & $\frac{\lambda-\lambda_{\text {ref }}}{\lambda_{\text {ref }}}$ \\
\hline REF-p & 0.29 & - \\
S3-p & 0.18 & $-38 \%$ \\
S5-p & 0.19 & $-34 \%$ \\
B3-p & 0.18 & $-38 \%$ \\
B5- p & 0.2 & $-31 \%$ \\
J3-p & 0.16 & $-45 \%$ \\
J5-p & 0.17 & $-41 \%$ \\
\hline
\end{tabular}

Table 8 shows the values of $\lambda$ for the examined materials (Figure 9).

The reference specimen, composed exclusively of sand and clay, has a higher thermal conductivity than specimens containing straw, basalt and jute fillers. The presence of the fiber involves a decrease in the final density of the product and a better behavior from the thermal point of view. Furthermore the final values of thermal conductivity $\lambda$ decrease from 30 to $40 \%$ with respect to the REF-p.

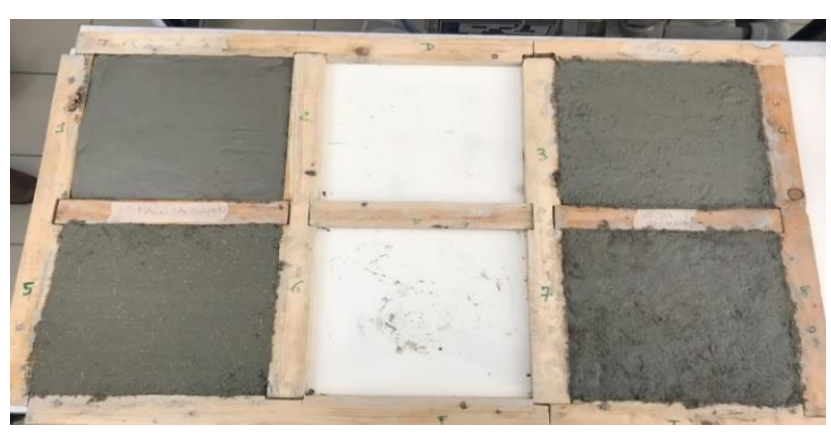

Figure 9. Specimens for thermal conductivity tests.

Comparing the obtained results with those of a previous work [12] it is possible to notice that the sand/clay matrix has a better thermal behavior than a cement mortar.

\section{CONCLUSIONS}

This paper presents an experimental study on adobe bricks with natural and biobased filler.

An amount of $20 \%$ of clay shows the best compromise between mechanical strength and shrinkage.

The use of straw filler in the clay/sand mixture causes a decrease in the maximum flexural and compressive strength (compared to the REF specimen). On the contrary mechanical performance of adobe bricks containing basalt and jute fibers increase with the filler amount, exhibiting a binder behavior with clay/sand mixture.

This is probably due to the ability of these type of fibers to restrain the extension of cracks, reduce the extent of stress concentration at the tip of cracks, and delay the growth rate of cracks.

Moreover the presence of the fiber involves a decrease in the final density of the product and a better behavior from the thermal point of view.

\section{ACKNOWLEDGMENT}

Author thanks to ILA LATERIZI s.r.l. from Bari (I) for the technical collaboration. 


\section{REFERENCES}

[1] Catalan G, Hegyi A, Dico C, Mircea C (2016). Determining the optimum addition of vegetable materials in adobe bricks. Procedia Technology 22: 259-265. https://doi.org/10.1016/j.protcy.2016.01.077

[2] El Fgaier F, Lafhay Z, Antczak E, Chapiseau C. (2016). Dynamic thermal performance of three types of unfired earth bricks. Applied Thermal Engineering 93: 377-383. https://doi.org/10.1016/j.applthermaleng.2015.09.009

[3] Cagnon H, Aubert JE, Coutand M, Magniont C. (2014). Hygrothermal properties of earth bricks. Energy and Buildings 80:

208-217. https://doi.org/10.1016/j.enbuild.2014.05.024

[4] Labat M, Magniont C, Oudhof N, Aubert JE. (2016). From the experimental characterization of the hygrothermal properties of straw-clay mixtures to the numerical assessment of their buffering potential. Building and Environment 97: 69-81. https://doi.org/10.1016/j.buildenv.2015.12.004

[5] Sanjay MR, Madhu P, Jawaid M, Senthamaraikannan P, Senthil S, Pradeep S. (2018). Characterization and properties of natural fiber polymer composites: a comprehensive review. Journal of Cleaner Production. 172: 566-581. https://doi.org/20.2026/j.jclepro.2017.10.101

[6] Di Bella G, Fiore V, Galtieri G, Borsellino C, Valenza A. (2014). Effects of natural fibers reinforcement in lime plasters (kenaf and sisal vs. Polypropylene). Construction and Building Materials 58: 159-165. https://doi.org/10.1016/j.conbuildmat.2014.02.026

[7] Sood M, Dwivedi G. (2017). Effect of fiber treatment on flexural properties of natural fiber reinforced composites: A review. Egyptian Journal of Petroleum. https://doi.org/10.1016/j.ejpe.2017.11.005

[8] Jordan W, Chester P. (2017). Improving the properties of banana fiber reinforced polymeric composites by treating the fibers. Procedia Engineering 200: 283-289. https://doi.org/10.1016/j.proeng.2017.07.040

[9] Iorio M, Santarelli ML, González-Gaitano G, GonzálezBenito J. (2018). Surface modification and characterization of basalt fibers as potential reinforcement of concretes. Applied Surface Science 427: 1248-1256.

https://doi.org/10.1016/j.apsusc.2017.08.196

[10] Alba MB, Cardinale T, De Fazio P, Lista GF, Sposato C. (2016). Tests for the characterization of fiber reinforced autoclaved aerated concrete. In: Proceedings of ECCM17-17 $7^{\text {th }}$ European Conference on Composite Materials Munich, Germany, pp. 1-7.

[11] Cardinale T, Arleo G, Bernardo F, Feo A, De Fazio P. (2017). Thermal and mechanical characterization of panels made by cement mortar and sheep's wool fibres. $\begin{array}{llll}\text { Energy } & \text { Procedia 159-169. }\end{array}$ https://doi.org/10.1016/j.egypro.2017.11.132

[12] Cardinale T, Arleo G, Bernardo F, Feo A, De Fazio P. (2017). Investigations on thermal and mechanical properties of cement mortar with reed and straw fibers. International Journal of Heat and Technology 35: S375S382. https://doi.org/10.18280/ijht.35Sp0151

[13] González D. (2014). Energy and carbon embodied in straw and clay wall blocks produced locally in the Andean Patagonia. Energy and Buildings 70: 15-22. https://doi.org/10.1016/j.enbuild.2013.11.003

[14] Razmi, Mirsayar MM. (2017). On the mixed mode I/II fracture properties of jute fiber-reinforced concrete. Construction and Building Materials 148: 512-520. https://doi.org/10.1016/j.conbuildmat.2017.05.034

[15] Zhou X, Hamidreza Ghaffar S, Dong W, Olayinka, Fan M. (2013). Fracture and impact properties of short discrete jute fibre-reinforced cementitious composites. Material and Design 49: 35-47. https://doi.org/10.1016/j.matdes.2013.01.029

[16] Ashour T, Korjenic A, Korjenic S, Wu W. (2015). Thermal conductivity of unfired earth bricks reinforced by agricultural wastes with cement and gypsum. Energy and Buildings 104: 139-146. https://doi.org/10.1016/j.enbuild.2015.07.016

[17] Xie Y, Hill CAS, Xiao Z, Militz H, Mai C. (2010). Silane coupling agents used for natural fiber/polymer composites: A review. Composites Part A: Applied Science and Manufacturing 41: 806-819. https://doi.org/10.1016/j.compositesa.2010.03.005

[18] Carbonaro S, Tedesco F, Thiebat S, Fantucci V, Serra, Dutto M. (2016). An integrated design approach to the development of a vegetal-based thermal plaster for the energy retrofit of buildings. Energy and Buildings 124: 46-59. https://doi.org/10.1016/j.enbuild.2016.03.063

[19] Brouard Y, Belayachi N, Ranganathan M, Hoxha D, Méo S. (2017). Experimental assessment of hygrothermal properties of clay - sunflower (helianthus annuus) and rape straw (brassica napus) bio-composites. In: Proceedings of the 2st International Conference on Biobased Building Materials, Clermont-Ferrand, France, ICBBM, pp. 376-380.

[20] Liu J, Zhou H, Ouyang P. (2013). Effect of straw mixing amount on mechanical properties of admixture adding hollow block. Journal of Wuhan University of Technology-Mater. Sci. 28(3): 508-513. https://doi.org/508-513.10.1007/s11595-013-0722-5

[21] McGregor F, Heath A, Maskell D, Fabbri A, Morel JC. (2015). A review on the buffering capacity of earth buildings materials. Proceedings of the Institution of Civil Engineers-Construction Materials 169(5): 241-251. https://doi.org/10.1680/jcoma.15.00035

\section{NOMENCLATURE}

$\mathrm{N}$

V

F

$\mathrm{f}$

1

b

d

\section{Greek symbols}

$\lambda$

$\Delta \mathrm{T}$

$\Phi$

$\sigma$ calibration factor, dimensionless potential difference between the transducers maximum load applied, $\mathrm{N}$ flexural strength, $\mathrm{N} \cdot \mathrm{mm}^{-2}$ distance between the axes of the support rollers, $\mathrm{mm}$ width of specimen, $\mathrm{mm}$ depth of the specimen, mm

thermal conductivity, $\mathrm{W} \cdot \mathrm{m}^{-1} \cdot \mathrm{K}^{-1}$ temperature difference between the two faces of the plates, $K$

heat flux, $\underline{\mathrm{W}}$ compressive tension, $\mathrm{MPa}$ deformation, dimensionless 
Subscripts

$\mathrm{p}$

Nanoparticle

f

nf

fluid (pure water)

Nanofluid 